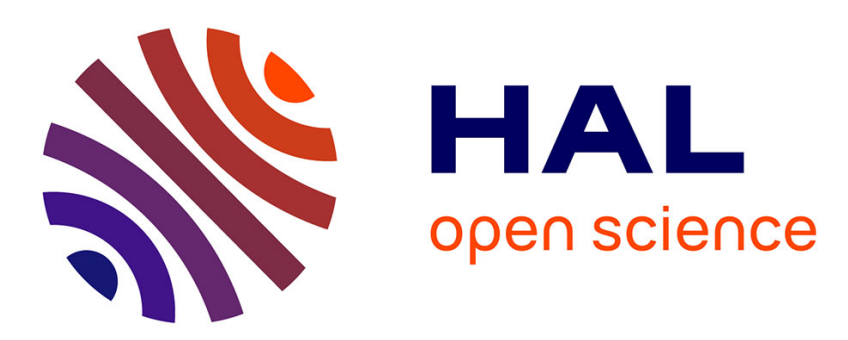

\title{
Tuning Surface Chirality of Adsorbed Gly-Pro Dipeptide/Cu(110) by Changing its Chemical Form via Electrospray Deposition.
}

Christophe Méthivier, Hervé Cruguel, Dominique Costa, Claire-Marie Pradier, Vincent Humblot

\section{To cite this version:}

Christophe Méthivier, Hervé Cruguel, Dominique Costa, Claire-Marie Pradier, Vincent Humblot. Tuning Surface Chirality of Adsorbed Gly-Pro Dipeptide/Cu(110) by Changing its Chemical Form via Electrospray Deposition.. Langmuir, 2016, 32 (51), pp.13759-13763. 10.1021/acs.langmuir.6b03553 . hal-01401619

\section{HAL Id: hal-01401619 https://hal.sorbonne-universite.fr/hal-01401619}

Submitted on 23 Nov 2016

HAL is a multi-disciplinary open access archive for the deposit and dissemination of scientific research documents, whether they are published or not. The documents may come from teaching and research institutions in France or abroad, or from public or private research centers.
L'archive ouverte pluridisciplinaire HAL, est destinée au dépôt et à la diffusion de documents scientifiques de niveau recherche, publiés ou non, émanant des établissements d'enseignement et de recherche français ou étrangers, des laboratoires publics ou privés. 


\section{Introduction}

Adsorption of biomolecules such as amino acids and peptides on surfaces is of the highest importance in the understanding of biointerfacial phenomena ${ }^{1}$, e.g. for the mystery of origin of Life, in the fields of biocompatibility and chiral recognition ${ }^{2}$, to cite a few. Chiral recognition is particularly intriguing having in mind the omnipresence of homochirality in biological systems; note also the well-known and remarkable chiral-sensitivity of the human body, displaying physiological answers so different depending of the biomolecule enantiomeric form ${ }^{3}$.

Although chirality is now better understood at the molecular level, fundamental questions remain concerning the transfer of the chirality from one molecule to a molecule-solid interface, or from one reactant to a product. As an example, for an asymmetric synthesis reaction to occur, the enantioselectivity must be brought on by the initial presence, during the reaction, of a chiral compound (initiator) ${ }^{4}$. In biology, the majority of biomolecules are of one same chiral form, homochirality being apparently critical for life as we know it, but how did it appear in the first place?

Homochiral macro-molecules (and Life) have evolved, because, once, there must have been a mechanism which could discriminate between the molecular sub- units from their mirror images, and construct the macromolecules from the sub-units of dictated chirality. In all cases, one key parameter in this mechanism is molecular recognition, where the chiral factor seems to be determining. Chiral recognition at an interface depends on specific and defined arrangement of units in complementary structures interacting together via short range interactions, likely multiple weak forces such as hydrogen bonds ${ }^{5}$. Another factor that can imprint surface chirality lies on the structure of the chiral molecule which needs to have the right size. For instance by adding 1 of 2 carbons to a given molecule (ca. 2amino-1-ethanol, -propanol or -butanol) the expression of surface chirality on $\mathrm{Cu}(100)$ will change drastically ${ }^{6}$.

Over the last 15 years, adsorption of amino acids and small peptides on metal surfaces have been studied extensively, with the objective of unravelling their chemistry, adsorption modes, as well as their 2D (chiral) supramolecular assemblies ${ }^{7}$. No doubt that understanding, at the fundamental level, the various types of existing biomolecule-metallic surface interactions is a clue to explain, maybe predict, the surface arrangement and reactivity ${ }^{7-10}$. It is, in particular, clear that chiral supramolecular structures are driven by intermolecular chiral recognition processes ${ }^{11}$. In the other hand, surface chirality and chiral recognition enable to 
design new 2D patterns and in certain extend to choose to express only one preferred surface-chirality. This last point was explored over 10 years ago first by Parschau et al. by LEED ${ }^{12}$, thus by STM by Raval and co-workers ${ }^{13}$ via the "soldier-sergeant" effect where only a small amount of chiral tartaric acid (TA) forced non-chiral succinic acid arrays(SU) into only one surface-chirality while both enantiomorphous SU domains were present without any TA molecules. A second example of surface-chirality tuning was reported when a small surface-enantiomeric excess of $(R, R)$-tartaric acid over the $(S, S)$-enantiomer, imbalances the racemic $\mathrm{SS} / \mathrm{RR}$ surface into predominant $(R, R)-\mathrm{TA}$ islands with smaller $(S, S)$-TA islands (together with some disordered areas). ${ }^{14}$ The same phenomenon was also observed by Fasel et al. using achiral molecules forming chiral surface assemblies; $\mathrm{M}$ - and P-enantiomers of heptahelicenes are equivalently present on $\mathrm{Cu}(111)$ surface when dosed from a racemic mixture, evidenced by the simultaneous presence of $\lambda$ and $\rho$ domains. However, when a small enantiomeric excess, as little as $0.08 \%$ of M-enantiomer, is implemented in the mixture, the surface assembly are thus doped into one $\rho$ domain of $2 \mathrm{D}$ superassembly ${ }^{15}$.

However, in these examples, the change of surface chirality is a consequence of the addition of a chiral "sergeants" in the case of achiral "soldiers" or the doping of racemic mixtures by one enantiomer. Surface chirality changes have also been observed upon coverage increase ${ }^{16,17}$ surface adlayers annealing ${ }^{18,19}$ or due to some other parameters such as relaxation time after adsorption/annealing ${ }^{20}$ or sublimation flux ${ }^{21}$. Several examples are summarised in two reviews by Barlow and Raval ${ }^{7}$ and by Ernst ${ }^{22}$.

However, it is only very rarely reported in the literature, if never, that investigations on surface chirality have been carried out on the influence of the chemistry of the molecular beam prior to the adsorption of a molecule on a surface. Therefore, in this paper, our objective was to willingly tune, or at least vary the chemical form of a given adsorbed peptide, in order to investigate the consequences on its binding mode and 2Darrangement on a well-defined copper surface. The $\mathrm{Cu}(110)$ surface was chosen for its known ability to create chiral domains upon adsorption of amino acids and peptides ${ }^{7,23}$. To vary the chemical form of peptides when landing on a surface, two very different deposition methods were applied under Ultra High Vacuum (UHV). The first method is conventional deposition from sublimation (using a Knüdsen cell or a crucible) into the gas phase, while the second one relies on the use of an electrospray ionisation or electron beam device allowing the deposition of molecular ions from the liquid phase. When using the first method, the chemistry of the molecule in the gas phase is fixed by its conformation in the crystalline phase (most often neutral for amino acids) only the reactivity of the metal surface 2 onto which it is adsorbed will influence the chemistry of the admolecule. For instance, methionine (neutral in the gas phase, will be adsorbed as zwitterionions on $\mathrm{Au}(111)$ or $\mathrm{Ag}(111)^{24,25}$ while it will be as anions on $\mathrm{Cu}$ surfaces $^{26,27}$. However, the use of electrospray ionisation devices offers an alternative quite seducing to the classical sublimation method. First of all, it allows evaporating under UHV conditions fragile and heavy molecules such as proteins, without breaking or damaging the molecules ${ }^{28,29}$. Furthermore, as the molecules to be adsorbed are in solution, it is easy to change their protonation state by varying the $\mathrm{pH}$ of the solution, or by changing the high voltage (HV) applied during the electrospray beam ${ }^{30}$.

Thus in these experiments, we have decided to use positive HV when dosing GP molecules to obtain a flux of positively charged molecules $\left(\mathrm{COOH} / \mathrm{NH}_{3}{ }^{+}\right)$and to compare it with the classical method where the molecules are neutral in the gas flux $\left(\mathrm{COOH} / \mathrm{NH}_{2}\right)$. The soobtained surfaces were fully characterized by $\mathrm{X}$-ray photoelectron spectroscopy (XPS), Polarization Modulation Reflection Absorption Infrared Spectroscopy (PM-RAIRS), Low Energy Electron Diffraction (LEED) and Scanning Tunelling Microscopy (STM); in addition, periodic DFT-D2 geometry optimizations were performed, see Supp Info section for more details.

\section{Results and Discussion}

The present study is focused on the surface chemistry and arrangement of the Gly-Pro di-peptide at an intermediate coverage, $\sim 1 / 3$ of a monolayer, based on studied carried out as a function of increasing GP coverage $^{31}$. Figure $\mathrm{S} 1$ of the Supplementary Information section shows the O1s and N1s XPS spectra taken on the surface after either Gly-Pro sublimation or ionization on $\mathrm{Cu}(110)$. The $\mathrm{O} 1 \mathrm{~s}$ regions show, in both cases, a single contribution at $532.1 \mathrm{eV}$ after sublimation and $531.5 \mathrm{eV}$, after ionization; these narrow peaks are both assigned to oxygen in carboxylate moieties. One should note that the O1s peak is shifted towards higher binding energies by about $0.5 \mathrm{eV}$ and accompanied by an enlargement of the fwhm (full width at halfmaximum) in the case of ESI deposition. This phenomenon can be explained by the anchoring mode of the GP molecules, where in the case of ESI, only 10 atom is in close vicinity to the surface, while after sublimation, the two $\mathrm{O}$ atoms interact, or atlas are very close to the $\mathrm{Cu}(110)$ surface. In addition, the change in the global charge of the molecule (-1 in the case of sublimation, 0 for $E S I$ ) may also influence the $B E$ of $O$ atoms. The N1s region, following adsorption by sublimation, exhibits two main contributions at $400.3 \mathrm{eV}$ and $398.6 \mathrm{eV}$; the former one is assigned to $\mathrm{N}$ in $\mathrm{NH}_{\text {amide }}$ or $\mathrm{NH}_{2}$ groups, while the latter is usually observed when a nitrogen atom is in strong interaction with a metallic surface $^{32}$. One can notice the non equivalence in 
weight of the two N1s contributions, which suggests 2 different anchoring mode of the GP molecules on the copper surface. This point will be explored in the following sections, mainly in the DFT part.

After adsorption by electrospray, the two N1s contribution, at $400.4 \mathrm{eV}$ and $401.1 \mathrm{eV}$ are rather attributed to $\mathrm{N}$ in $\mathrm{NH}$ or $\mathrm{NH}_{2}$ and in protonated $\mathrm{NH}_{3}^{+}$group, respectively. Again, here, one can notice the non equivalence of all N1s contributions, suggesting that some of the molecules are in a different chemical form. It has been calculated from the low $\mathrm{BE}$ contributions that less than $10 \%$ of the GP adsorbed molecules are present as anionic admolecules, likely interacting via the $\mathrm{N}$ atom thus explaining the low BE contribution.

These data enable to identify the chemical form of the adsorbed Gly-Pro molecules: after sublimation, Gly-Pro is mainly adsorbed under its anionic chemical form («A», $\mathrm{NH}_{2} / \mathrm{COO}^{-}$) with the $\mathrm{NH}_{2}$ terminal group being in interaction with the $\mathrm{Cu}(110)$ surface $^{31}$. Conversely, after electrospray deposition, most of the Gly-Pro molecules are adsorbed at the $\mathrm{Cu}(110)$ surface under their zwitterionic form («Z», $\left.\mathrm{NH}_{3}{ }^{+} / \mathrm{COO}^{-}\right)$.

When looking at the PM-RAIRS data obtained after deposition by sublimation or electrospray, Figure S2, one can see very different IR profiles indicating a change in the chemical form and/or orientation of the Gly-Pro molecules at the $\mathrm{Cu}(110)$ surface. Indeed, the anchoring modes of the molecules, and consequently their orientation can be deduced from the IR spectra ${ }^{7}$, 33. In the present case, after deposition by sublimation one principal IR peak arises at $1428 \mathrm{~cm}^{-1}$, assigned to the symmetric stretch of the $\mathrm{COO}^{-}$group, accompanied with a much smaller contribution for the asymmetric contribution at $1610 \mathrm{~cm}^{-1}$, suggesting an anchoring mode via both oxygen atoms of the carboxylate group $^{19}$. In opposition, when Gly-Pro is deposited via electrospray ionisation, one observes an inversion of the respective intensities of the asymmetric and symmetric contributions, at 1610 and $1400 \mathrm{~cm}^{-1}$ respectively. This dominating asymmetric contribution indicates a change in the orientation of the molecule with respect to the surface, with the GP molecule being now anchored to the surface via only one oxygen atom of the carboxylate moiety ${ }^{34}$. Looking now at the 2-dimensional arrangements, different adsorption geometries seems to propagate and dictate the peptide supramolecular assemblies. Figure 1 (a) and (c) shows the LEED data obtained for the Gly-Pro adsorbed as zwitterionic and anionic molecules, respectively. Two different unit cells are observed: after electrospray evaporation (left side of Figure 1), the LEED unit cell is depicted as a $(20,1$ 3) chiral unit cell, while the gas phase deposition surface leads to a larger (2 -1, 2 5) chiral unit cell (Figure 1 right side). The unit cell are reproduced on the adsorption model of Figure 1 (b) and (d); in (b) the chiral unit cell bears around half the size of the one exposed in (d), showing, in addition, different alignments with respect to the crystallographic axes.
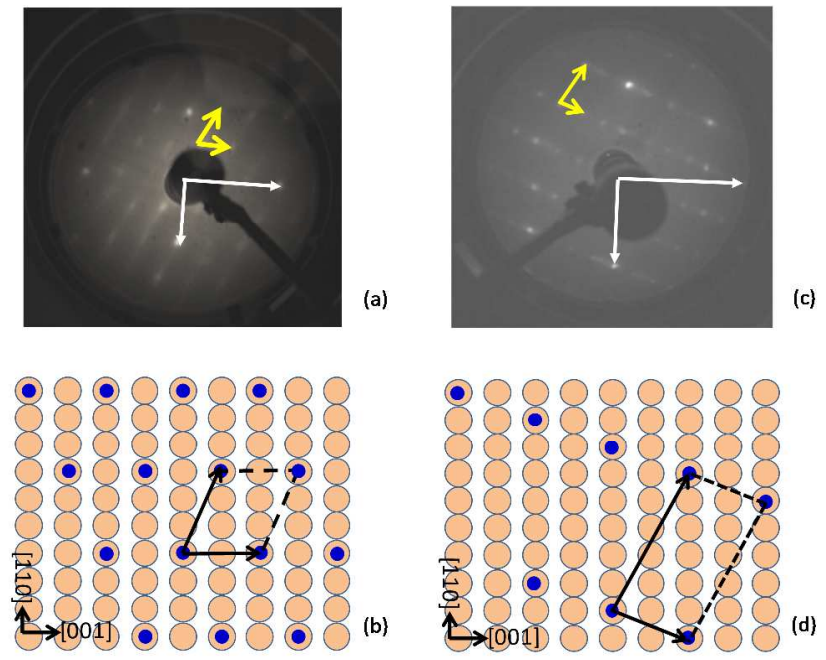

Figure 1. 2-Dimensional data of zwitterionic adsorbed Gly-Pro on $\mathrm{Cu}(110)$ (after electrospray) (a) and (b), and anionic (after sublimation) (c) and (d). (a) and (c) LEED data showing the chiral units cells (yellow lines), $(20,13)$ and $(2-1,25)$ for zwitterionic and anionic molecules, respectively. The white lines represent the $\mathrm{Cu}$ unit cells. (b) and (d) show the 2D adsorption model with the chiral unit cells joining blue dots. For details on the description of the LEED pattern see Ref. ${ }^{31}$.

These differences are even more visible on the STM images presented on Figures 2 (a) and (c). One can recognize the chiral unit cells depicted by the yellow lines, but the shapes of the 2D arrays are totally different. In the case of the anionic molecules, Figure 2 (c), the molecules are aligned, forming rows of dimers, while in the case of zwitterionic molecules, Figure 2 (a), the 2D arrays are forming islands of close-packed molecules. Using the STM images to draw profiles and calculate intermolecular distances, one can locate the molecules within the unit cells deduced from LEED diagrams; molecules are represented as diamonds and triangles in Figure 2 (b) and (d).

Finally, it is worth noting that ESI experiments with negative HV have also been carried out; the molecular beam was thus anionic $\left(\mathrm{COO}^{-} / \mathrm{NH}_{2}\right)$ and the adsorbed Gly-Pro molecules were also anions. When performing the STM analyses, we ended up with the same 2D arrays as those formed upon sublimation from the gas phase. 

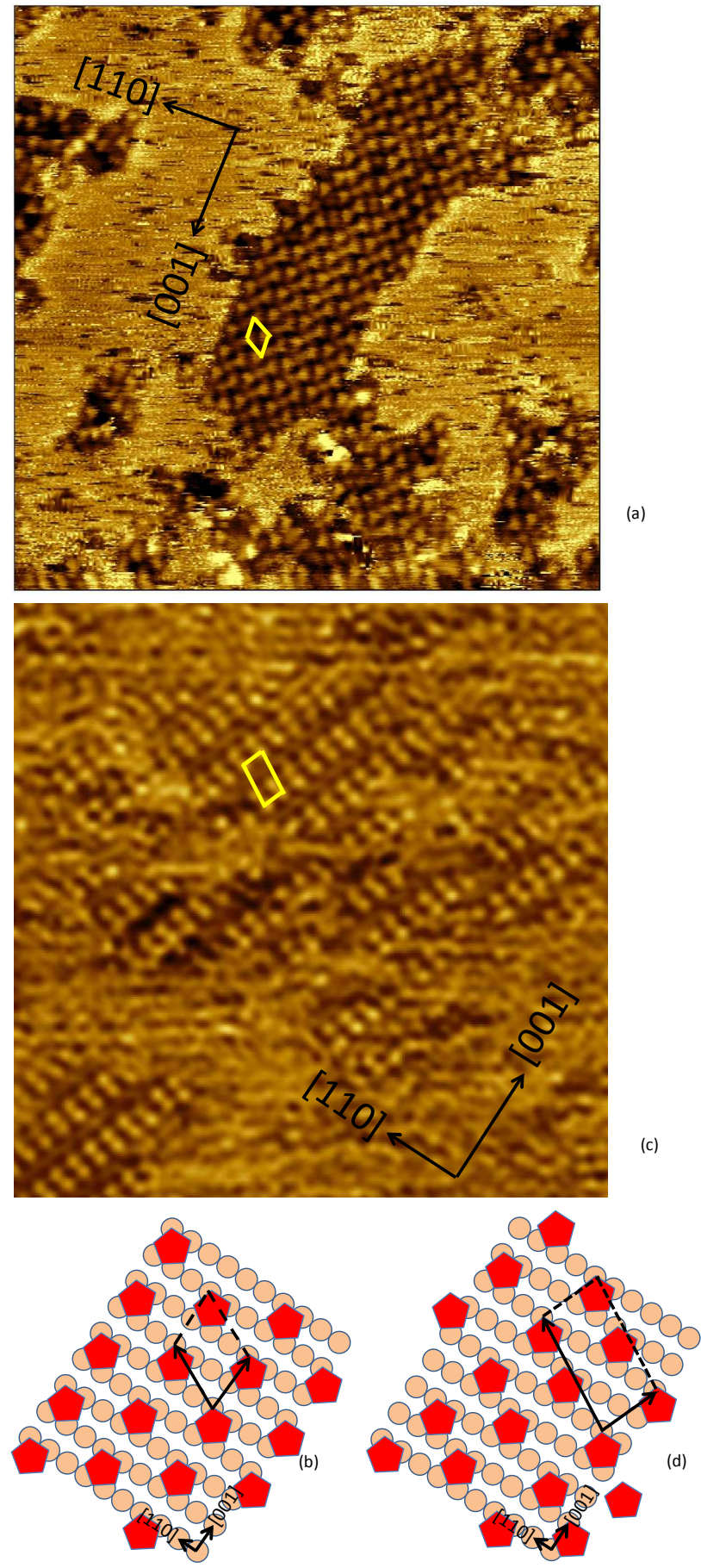

Figure 2. STM images of (a) zwitterionic Gly-Pro molecules $(Z)$ and (c) anionic Gly-Pro molecules (A) adsorbed at low coverage on $\mathrm{Cu}(110)$. The yellow lines show the chiral units cells, $(20,13)$ and $(2-1,25)$ for zwitterionic $(Z)$ and anionic $(A)$ surstructures, respectively. Images: $25 \mathrm{~nm} \times 25 \mathrm{~nm}$. (b) and (d) are the deduced adsorption models obtained from STM profiles measurements. Arbitrary schematic representation of GP molecules as pentagones. More details on the description of the STM data of anionic GP can be found on Ref. ${ }^{31}$

These geometrical arrangements are obviously related to different intermolecular interactions. To visualize the adsorbed molecules and address the issue of intermo- lecular interactions, we performed DFT calculations for both identified super-structures. They are reported in Figure $3(a-b)$ for the zwitterionic structure, " $Z$ ", and (cd) for the anionic structure, A. Starting from the known structures and the molecule chemical states deduced from spectroscopic data, different possible adsorption modes were explored. The $Z$ structure is composed of rows of interacting zwitterions adsorbed through the carboxylate moiety. The carboxylate can interact with $\mathrm{Cu}$ in a mono (one $\mathrm{O}$ of $\mathrm{COO}$ is adsorbed on $\mathrm{Cu}$ ) or a bidentate (both carboxylate $\mathrm{O}$ interact with $\mathrm{Cu}$ ) configuration. We found that the mode of adsorption of the carboxylate has a direct impact on the lateral interactions and therefore monitors the stabilization of the $\mathrm{NH}_{3}{ }^{+}$moiety. Indeed, in a bidentate adsorption where both carboxyl $\mathrm{O}$ are involved in a covalent bond with $\mathrm{Cu}$, an $\mathrm{H}$-bond is formed between $\mathrm{NH}_{3}{ }^{+}$and the neighbour peptide $\mathrm{O}$ (see figure S3 in Supp Infos). This configuration is less stable by $0.7 \mathrm{eV}$ than the unidentate $\mathrm{COO}^{-}$adsorption shown in Figure $3 \mathrm{a}-\mathrm{b}$. In the latter case, one carboxylate $\mathrm{O}$ accepts an $\mathrm{H}$-bond from the $\mathrm{NH}_{3}{ }^{+}$moiety of a neighbouring molecule). The Cu rows where adsorption occurs are separated by two empty $\mathrm{Cu}$ rows, which are distorted, evidencing a stressed surface. The energy of adsorption per $Z$ molecule is 3.3 $\mathrm{eV}$, which is composed of $2.35 \mathrm{eV}$ of cohesion in the layer and $0.95 \mathrm{eV}$ of layer-surface interaction. The $\mathrm{A}$ structure is more complex; the cell is larger, and contains dimers of anions. A preliminary study of adsorption of the isolated anions evidences a tridentate adsorption mode with both carboxylate $\mathrm{O}$ and the $\mathrm{NH}_{2}$ moiety in interaction with $\mathrm{Cu}$ (Figure 3c).

In this configuration, rows of adsorbed anions are formed (Figure 3c), with an adsorption energy of the anion of $4.8 \mathrm{eV}$. Then a neighbouring molecule can adsorb either in the same configuration, without $\mathrm{H}$ bonds to the previous molecule, or form a dimer, with $\mathrm{H}$-bond between the $\mathrm{NH}_{2}$ moiety and one carboxylate $\mathrm{O}$ of the neighbour molecule, (Figure 3d). In the dimer the energy of adsorption is $5.1 \mathrm{eV} /$ anion, thus by $0.6 \mathrm{eV}$ more stable than the tridentate adsorption of two anions. Indeed, lateral interactions in the dimer are 1.05 $\mathrm{eV}$, whereas the dimer-surface interaction accounts for $4.05 \mathrm{eV}$ per anion. In other words, there is a competition between molecule-molecule and molecule-surface interactions. 

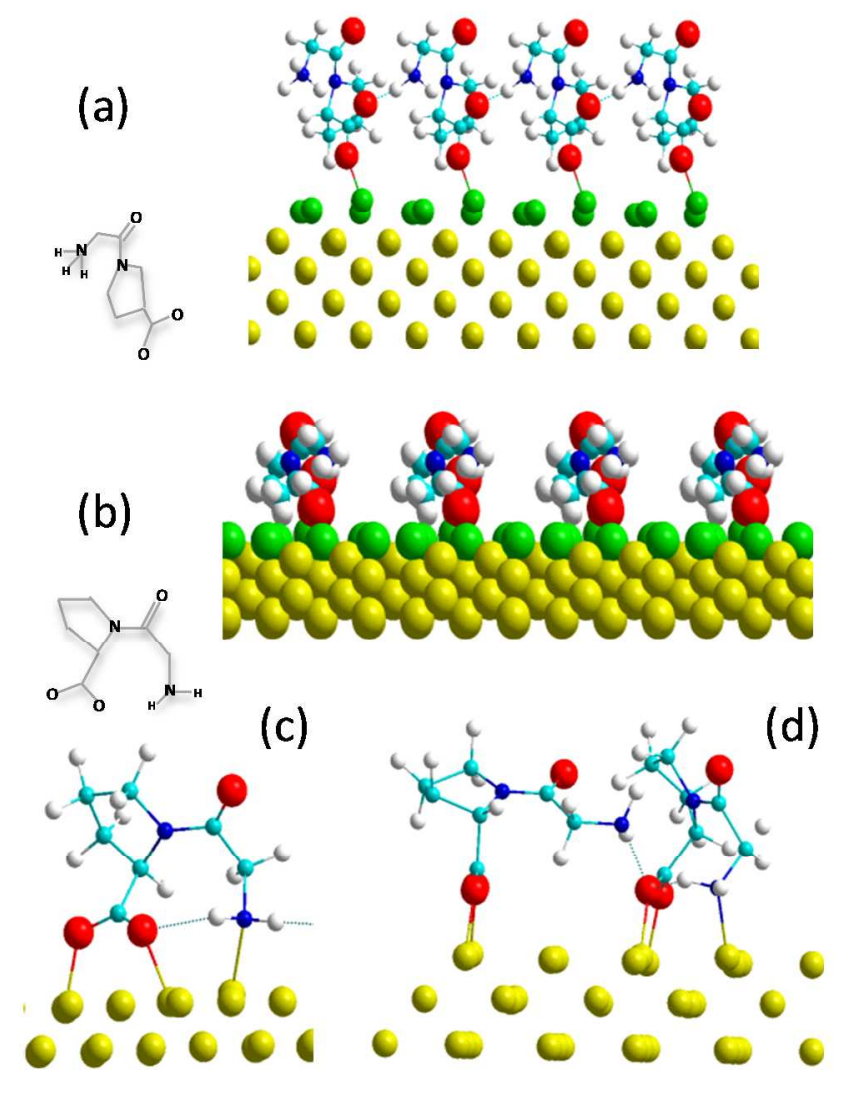

Figure 3.DFT obtained structures a),b) Zwitterionic structure, a) intermolecular interactions in one row, b) side view of different rows, c, d ) Anionic structure; snapshot on c) the tridentate molecule, d) the dimer adsorbed. Inserts are showing flat 2D sketches of the molecules drawn from their 3D model.

Finally, in both $Z$ and $A$ surstructures, (see the modelled surstructures in SI Figure S4) we find that the lateral interactions impact the geometry of adsorption, and that the formation of an ordered array induces a partial detachment from the surface, from bidentate to unidentate for $Z$ structure, and from tridentate to bidentate for the A structure, in order to reinforce cohesion in the molecular layer. Note also that, as expected, the $Z$ layer is much more cohesive than the $A$ dimers, but $A$ dimers interact most with the surface.

\section{Conclusions}

By changing the mode of admission of a Gly-Pro peptide in UHV, we were able to adsorb either anionic or zwitterionic molecules on a $\mathrm{Cu}(110)$ surface. These two forms interact with the surface in different modes and form different surface chiral arrangements. By combining PM-RAIRS data and DFT calculations, we propose the formation of either rows of dimers, stabilized by the underlying surface, or aggregates of molecules resulting from possible intermolecular interactions. Limited intermolecular interactions (when all reactive groups interact with the surface) prove to let molecule-surface interactions dictate the surface arrangement. These findings prove that it is possible to influence, change and even choose the 2D chirality of a surface by making the right choice of the chemical form of adsorbed molecules. We demonstrated that playing around with the admission mode enables it. This, by the way, shows the potential of sending (macro)molecules under UHV by an electrospray device. The resulting surface assemblies are profoundly different, related to the nature and strength of intermolecular forces. One may anticipate significant consequences upon the further reactivity of both types of surfaces.

\section{ASSOCIATED CONTENT}

Supporting Information for this article is given via a link at the end of the document PM-RAIRS and XPS data are presented as well as experimental details. Details of DFT calculations are also presented.

\section{AUTHOR INFORMATION}

\section{Corresponding Author}

*Vincent Humblot, vincent.humblot@upmc.fr.

\section{Author Contributions}

The manuscript was written through contributions of all authors. / All authors have given approval to the final version of the manuscript.

\section{ABBREVIATIONS}

UHV, Ultra High Vacuum; GP, Gly-Pro; .LEED, Low Electron Energy Diffraction; STM, Scanning Tunneling Microscopy; TA, Tartaric Acid; SU, Succinic Acid; HV, high Voltage; XPS, X-ray Photoelectron Spectroscopy; PM-RAIRS, Polarization Modulation Reflection Absorption Infrared Spectroscopy; DFT, Density functional Theory; fwhm, full width at half maximum.

\section{REFERENCES}

(1) Gray, J. J. The Interaction of Proteins with Solid Surfaces. Curr. Opin Struct. Biol. 2004, 14, 110-115.

(2) Kasemo, B. Biological surface science. Surf. Sci. 2002, 500, (1-3), 656-677.

(3) Brown, G. E.; Henrich, V. E.; Casey, W. H.; Clark, D. L.; Eggleston, C.; Felmy, A.; Goodman, D. W.; Gratzel, M.; Maciel, G.; McCarthy, M. I.; Nealson, K. H.; Sverjensky, D. A.; Toney, M. F.; Zachara, J. M. Metal oxide surfaces and their interactions with aqueous solutions and microbial organisms. Chem. Rev. 1999, 99, (1), 77-174.

(4) Baiker, A. Reflections on chiral metal surfaces and their potential for catalysis. Catal. Today 2005, 100, (1-2), 159-170.

(5) Berg, J. M.; Tymoczko, J. L., Biochemistry. 5th ed.; (Ed: W.H. Freeman): New-York, 2002.

(6) Ronci, F.; Gatti, R.; Caponi, G.; Colonna, S.; Galeotti, G.; Catone, D.; Turchini, S.; Prosperi, T.; Zema, N.; Palma, A.; Gori, P.; Contini, G. Organizational chirality expression as a function of the chirality measure of simple amino alcohols on $\mathrm{Cu}(100)$. Surf. Sci. 2014, 629, 41-47.

(7) Barlow, S. M.; Raval, R. Complex organic molecules at metal surfaces: bonding, organisation and chirality. Surf. Sci. Rep. 2003, 50, (6-8), 201-341.

(8) Hasselström, J.; Karis, O.; Weinelt, M.; Wassdahl, N.; Nilsson, A.; Nyberg, M.; Pettersson, L. G. M.; Samant, M. G.; Stöhr, J. The adsorption structure of glycine adsorbed on $\mathrm{Cu}(110)$; comparison with formate and acetate/Cu(110). Surf. Sci. 1998, 407, (1-3), 221-236. 
(9) Jones, T. E.; Baddeley, C. J.; Gerbi, A.; Savio, L.; Rocca, M.; Vattuone, L. Molecular ordering and adsorbate induced faceting in the $\mathrm{Ag}\{110\}$-(S)-glutamic acid system. Langmuir 2005, 21, (21), 9468-9475. (10) Kühnle, A.; Linderoth, T. R.; Hammer, B.; Besenbacher, F. Chiral recognition in dimerization of adsorbed cysteine observed by scanning tunnelling microscopy. Nature 2002, 415, (6874), 891-893.

(11) Lingenfelder, M.; Tomba, G.; Costantini, G.; Ciacchi, L. C.; De Vita, A.; Kern, K. Tracking the chiral recognition of adsorbed dipeptides at the single-molecule level. Angew. Chem., Int. Ed. 2007, 46, (24), 4492-4495.

(12) Parschau, M.; Romer, S.; Ernst, K. H. Induction of Homochirality in Achiral Enantiomorphous Monolayers. J. Am. Chem. Soc. 2004, 126, $15398-15399$

(13) Liu, N.; Haq, S.; Darling, G.; Raval, R. Direct Visualization of Enantiospecific Substitution of Chiral Guest Molecules into Heterochiral Molecular Assemblies at Surfaces. Angew. Chem., Int. Ed. 2007, 46, (40), 7613-7616.

(14) Haq, S.; Liu, N.; Humblot, V.; Jansen, A. P. J.; Raval, R. Drastic symmetry breaking in supramolecular organization of enantiomerically unbalanced monolayers at surfaces. Nat. Chem. 2009, 1, 409-414.

(15) Fasel, R.; Parschau, M.; Ernst, K. H. Amplification of chirality in two-dimensional enantiomorphous lattices. Nature 2006, 439, 449-452.

(16) Barlow, S. M.; Louafi, S.; Le Roux, D.; Williams, J.; Muryn, C.; Haq, S.; Raval, R. Polymorphism in supramolecular chiral structures of Rand S-alanine on $\mathrm{Cu}(110)$. Surf. Sci. 2005, 590, (2-3), 243-263.

(17) Contini, G.; Gori, P.; Ronci, F.; Zema, N.; Colonna, S.; Aschi, M.; Palma, A.; Turchini, S.; Catone, D.; Cricenti, A.; Prosperi, T. Chirality Transfer from a Single Chiral Molecule to 2D Superstructures in Alaninol on the $\mathrm{Cu}(100)$ Surface. Langmuir 2011, 27, (12), 7410-7418.

(18) Jones, T. E.; Urquhart, M. E.; Baddeley, C. J. An investigation of the influence of temperature on the adsorption of the chiral modifier, (S)glutamic acid, on Ni\{111\}. Surf. Sci. 2005, 587, (1-2), 69-77.

(19) Lorenzo, M. O.; Haq, S.; Bertrams, T.; Murray, P.; Raval, R.; Baddeley, C. J. Creating chiral surfaces for enantioselective heterogeneous catalysis: R,R-Tartaric acid on $\mathrm{Cu}(110)$. J. Phys. Chem. B 1999, 103, (48), $10661-10669$

(20) Lorenzo, M. O.; Humblot, V.; Murray, P.; Baddeley, C. J.; Haq, S.; Raval, R. Chemical Transformations, Molecular Transport, and Kinetic Barriers in Creating the Chiral Phase of (R,R)-Tartaric Acid on $\mathrm{Cu}(110)$. J. Catal. 2002, 205, 123-134.

(21) Jones, T. E.; Baddeley, C. J. A RAIRS, STM and TPD study of the $\mathrm{Ni}\{111\} / \mathrm{R}, \mathrm{R}$-tartaric acid system: Modelling the chiral modification of $\mathrm{Ni}$ nanoparticles. Surf. Sci. 2002, 513, (3), 453-467.

(22) Ernst, K. H. Molecular chirality at surfaces. Phys. Status Solidi B 2012, 249, (11), 2057-2088.

(23) Lorenzo, M. O.; Baddeley, C. J.; Muryn, C.; Raval, R. Extended surface chirality from supramolecular assemblies of adsorbed chiral molecules. Nature 2000, 404, (6776), 376-379.
(24) Naitabdi, A.; Humblot, V. Chiral self-assemblies of amino-acid molecules: D- and L-methionine on $\mathrm{Au}(111)$ surface. Appl. Phys. Lett. 2010, 97, (22), 223112.

(25) Schiffrin, A.; Riemann, A.; Auwarter, W.; Pennec, Y.; WeberBargioni, A.; Cvetko, D.; Cossaro, A.; Alberto, M.; Barth, J. V. Zwitterionic self-assembly of L-methionine nanogratings on the $\mathrm{Ag}(111)$ surface. Proc. Natl. Acad. Sci. USA 2007, 104, (13), 5279-5284.

(26) Méthivier, C.; Humblot, V.; Pradier, C.-M. L-Methionine adsorption on $\mathrm{Cu}(110)$, binding and geometry of the amino acid as a function of coverage. Surf. Sci. 2015, 632, (0), 88-92.

(27) Schiffrin, A.; Reichert, J.; Pennec, Y.; Auwarter, W.; WeberBargioni, A.; Marschall, M.; Dell'Angela, M.; Cvetko, D.; Bavdek, G.; Cossaro, A.; Morgante, A.; Barth, J. V. Self-Assembly of L-Methionine on $\mathrm{Cu}(111)$ : Steering Chiral Organization by Substrate Reactivity and Thermal Activation. J. Phys. Chem. C 2009, 113, (28), 12101-12108.

(28) Deng, Z.; Thontasen, N.; Malinowski, N.; Rinke, G.; Harnau, L.; Rauschenbach, S.; Kern, K. A Close Look at Proteins: Submolecular Resolution of Two- and Three-Dimensionally Folded Cytochrome $\mathrm{c}$ at Surfaces. Nano Letters 2012, 12, (5), 2452-2458.

(29) Rauschenbach, S.; Rinke, G.; Malinowski, N.; Weitz, R. T.; Dinnebier, R.; Thontasen, N.; Deng, Z.; Lutz, T.; de Almeida Rollo, P. M.; Costantini, G.; Harnau, L.; Kern, K. Crystalline Inverted Membranes Grown on Surfaces by Electrospray Ion Beam Deposition in Vacuum. Adv. Mater. 2012, 24, (20), 2761-2767.

(30) Wang, R.; Zenobi, R. Evolution of the Solvent Polarity in an Electrospray Plume. J. Am. Soc. Mass Spectrom. 2010, 21, (3), 378-385.

(31) Cruguel, H.; Méthivier, C.; Pradier, C.-M.; Humblot, V. Surface Chirality of Gly-Pro Dipeptide Adsorbed on a $\mathrm{Cu}(110)$ Surface. Chirality 2015, 27, (7), 411-416.

(32) Feyer, V.; Plekan, O.; Tsud, N.; Lyamayev, V.; Chab, V.; Matolin, V.; Prince, K. C.; Carravetta, V. Adsorption Structure of Glycyl-Glycine on $\mathrm{Cu}(110)$. J. Phys. Chem. C 2010, 114, (24), 10922-10931.

(33) Barlow, S. M.; Haq, S.; Raval, R. Bonding, organization, and dynamical growth behavior of tripeptides on a defined metal surface: Tri-Lalanine and tri-L-leucine on $\mathrm{Cu}\{100\}$. Langmuir 2001, 17, (11), 32923300 .

(34) Humblot, V.; Haq, S.; Muryn, C.; Hofer, W. A.; Raval, R. From local adsorption stresses to chiral surfaces: (R,R)-tartaric acid on $\mathrm{Ni}(110) . J$. Am. Chem. Soc. 2002, 124, (3), 503-510. 
Insert Table of Contents artwork here
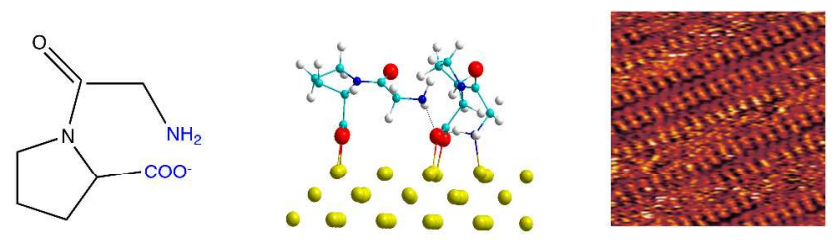

Gly-Pro/Cu(110)
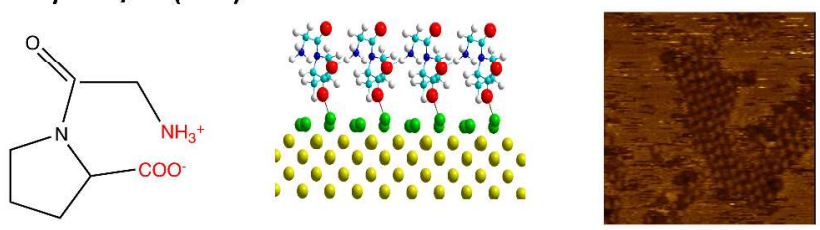

20

21

22

23

24

25

26

27

28

29

30

31

32

33

34

35

36

37

38

39

40

41

42

43

44

45

46

47

48

49

50

51

52

53

54

55

56

57

58

59

60 